\title{
Experimental investigations of the roll load and roll torque when high strength steel is roll formed
}

\author{
Michael Lindgren \\ Material Science, Dalarna University, 78170 Borlänge, Sweden
}

\begin{abstract}
The cold roll forming process is a highly efficient process used to produce profiles for many applications, for example vehicles, buildings, domestic machines, etc. Therefore, its market share is increasing every year. Many of the above products are already today made of high strength steel and the usage of these materials will likely continue to increase.

The objectives of this project are to find how the roll load and roll torque are influenced by the yield strength of the material. Full-scale experiments have been performed. U-channels made of different materials from mild to ultra high strength steels have been formed. The roll torque is measured during the process using a torque sensor mounted between the tool and the power transmission. Used power is also calculated with help of the motor current. The roll load is measured with load cells mounted on both side of the roll forming tool.

The experimental result will increase the understanding of the specific conditions for roll forming steels with increasing yield strength. The result can be used to support the roll machine designer to choose machine elements and power unit for these applications. Furthermore, the result can also be compared with finite element simulations in order to improve and validate simulation models.
\end{abstract}

(C) 2007 Elsevier B.V. All rights reserved.

Keywords: Cold roll forming; High strength steel; Roll torque; Roll load

\section{Introduction}

Roll forming is a bending operation where the bending occurs in several forming steps from an undeformed strip to a finished profile. Every forming step consists of a pair of forming tools that rotate and drive the strip forward during the forming. Today one can find roll formed products in many different fields as buildings, vehicles, furniture, etc. The use of the process increases continuously due to the efficiency of the process.

Despite the fact that roll forming is a common sheet metal forming process and used worldwide there are relatively few publications about the process. The explanation may be the complexity of the deformation behaviour in the process despite its visual simplicity. There are numerous factors which can influence the roll forming design, for example unlimited variation of the shape of the profile. Nevertheless, some researchers have developed simple models [1,2], and in a newly released book Halmos [3] described how this process can be used successfully.

Finite element simulations have been used a long time in sheet metal forming to develop forming tools. However, this has

E-mail address: mld@du.se. not been the case for the roll forming processes due to limited computer capacity. Only in recent years has this became possible [4-6], and today roll forming computer aided engineering system [7], can offer simplified finite element models for simulations. From these models the roll load and roll torque can be received and compared with measurement and thereby validated.

Bhattacharyya et al. [8] suggested an analytic model for the roll load in a single roll station, Eq. (1), when a U-channel was formed:

$F=s \sqrt{\frac{2 t^{3} \theta^{3} a}{3 \sin (\theta)}}$

where $t$ is the thickness, $s$ the yield strength, $a$ the flange length and $\theta$ is the bend angle.

The model was compared with measurements for mild steel and aluminium for different thickness and bend angle. The conclusion was that the error between the model and the measurements was within $0-20 \%$.

The current work is an investigation of the roll forming of a U-channel of different sheet metals, ranging from mild to ultra high strength steel. Roll load and roll torque have been measured during the forming. The results from these measurements can 
be used to validate finite element models, can support the roll machine designer to choose machine elements and power unit when the strength of the material increases.

\section{Experimental details}

\subsection{The roll forming mill}

A standard roll forming mill [3] (Fig. 1) is used to investigate the roll load and roll torque. The mill has six forming stands and universal joint driven shafts are used to run the tools. The power unit is a $15 \mathrm{~kW}$ frequency controlled three-phase motor. No driven top shafts are used.

\subsection{The measurement equipment}

Two load cells of donut type from Honeywell Sensotec Sensors are mounted between the tools and the forming stands in order to measure the roll load (Fig. 1). The maximum roll load that the load cells can measure is $17,800 \mathrm{~N}$. The roll torque is measure with a torque sensor from Burster, which can measure up to $75 \mathrm{Nm}$. The torque sensor is mounted between the power transmission and the lower forming tool (Fig. 1). An encoder is used to measure the velocity of the profile. The motor current is measured by a frequency changer.

The data acquisition equipment is from NATIONAL INSTRUMENT ${ }^{\mathrm{TM}}$ where the used software is LabVIEW ${ }^{\mathrm{TM}}$

\subsection{The profile}

The U-channel is formed in four steps from an undeformed strip to a bend angle of $80^{\circ}$. The undeformed strip has a width of $84 \mathrm{~mm}$ and a thickness ranging from 1.0 to $1.5 \mathrm{~mm}$. The bending method is "constant arc length" [9] which means that the bend radius will be different for every forming step but the arc length of the bend corner will be constant. The final profile, bend angle $80^{\circ}$, has a flange length of $23.3 \mathrm{~mm}$, a web of $23.3 \mathrm{~mm}$ and a final radius of $5.55 \mathrm{~mm}$ at the neutral layer when $1 \mathrm{~mm}$ strip is formed.

\subsection{The material}

Seven different materials have been tested, four carbon steels and three stainless steels (Table 1).

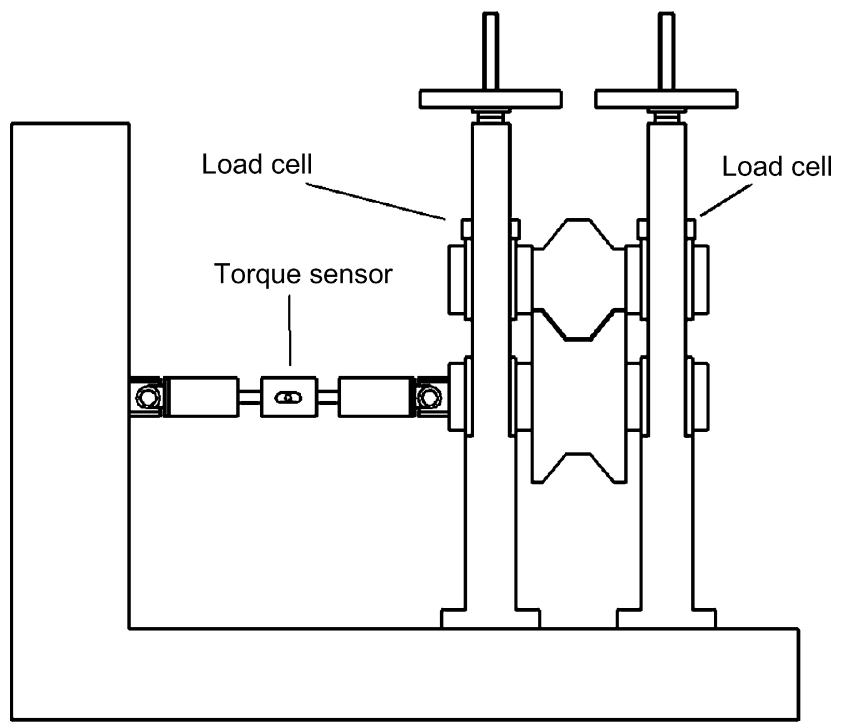

Fig. 1. A standard roll forming mill is used to do experiments, the roll load is measured with load cells and the roll torque is measured with a torque sensor during a forming of different steels.
Table 1

The materials that have been tested are Docol, DC01 (carbon steel) and HyTens, SS2333 (stainless steel)

\begin{tabular}{llc}
\hline Material & Thickness $(\mathrm{mm})$ & $R_{\mathrm{P} 0.2}(\mathrm{MPa})$ \\
\hline DC01 & 1.46 & 193 \\
Docol 800DP & 1.48 & 533 \\
Docol 1200M & 1.46 & 1129 \\
Docol 1200M & 1.22 & 1119 \\
HyTens 1200 & 1.0 & 1018 \\
SS2333 & 1.0 & 301 \\
HyTens X & 1.0 & 286 \\
\hline
\end{tabular}

\subsection{The experimental set-up}

The strip is formed through a single forming step with varying bend angles, $20^{\circ}, 40^{\circ}, 60^{\circ}$ and $80^{\circ}$, during the forming the load and torque are measured. The forming passes before and after the single step are only used as flat rolls $\left(0^{\circ}-\theta^{\circ}-0^{\circ}\right)$. This is done in order to eliminate the influences on torque from other forming steps. The bending angle increment is dependent on the amount of spring back from the previous forming step.

The load and the torque are dependent on the tolerance between the thickness of the formed material and the roll gap between the tools. The load and the torque will be very large if the clearance between the upper and lower tool is too small. To avoid this, the profile is rolled in between the tool and the roll load is increased until the roll gap is between 0.1 and $0.15 \mathrm{~mm}$ larger then the thickness of the formed material, this is checked with a feeler gage.

The measurement starts when the profile rests on both the flat rolls before and after the forming step. The velocity of the profile that is used during the measurement is $9.7 \mathrm{~m} / \mathrm{min}$. A lubricant is used in abundance and the surface finish is $R_{\mathrm{Z}}=1 \mu \mathrm{m}$.

\section{Result}

In Fig. 2 are the measured roll load and the roll torque presented for Docol $1200 \mathrm{M}$, thickness $1.46 \mathrm{~mm}$. The mean value is calculated for every experiment in Fig. 2 during the sample time 30 to sample time 60 . A new mean value and standard deviation is then calculated for the mean value from experiments 1 to 3 for the load and the torque. These values are presented for all used materials in Table 2.

\subsection{Models}

In the experiments, for example bend angle $60^{\circ}$, have materials with different thickness and virgin yield strength been used, if one assumes that only these parameters influence the load and the torque a model can be created as Eqs. (2) and (3):

$$
\begin{aligned}
& F_{\text {Load }}=k_{1}(\theta) t^{k_{2}} s^{k_{3}} \\
& T_{\text {Torque }}=k_{4}(\theta) t^{k_{5}} s^{k_{6}}
\end{aligned}
$$

where $t$ is the thickness of the material, $s$ the yield strength of the material, $k_{i}$ the constants and exponents and $\theta$ is the used bend angle, in this case $60^{\circ}$.

In Fig. 3 are the models, Eqs. (2) and (3), compared with experiments when the bend angle $60^{\circ}$ is used. The constants and the exponents in the Fig. 3 are $k_{1}(\theta)=88, k_{4}(\theta)=0.38$, $k_{2}=k_{5}=2.1$ and $k_{3}=k_{6}=0.57$. This is somewhat different from 


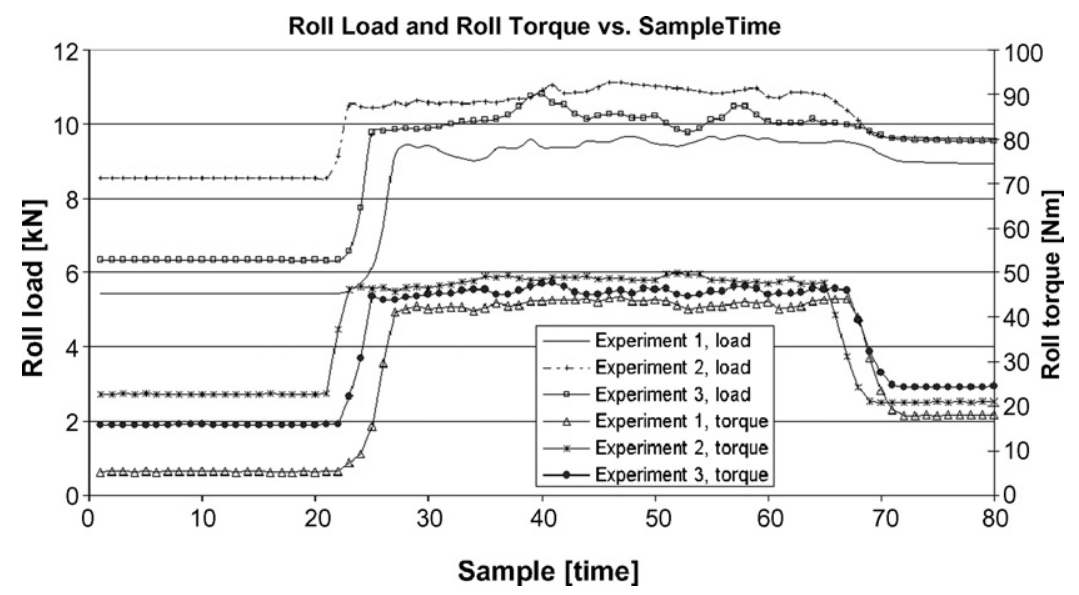

Fig. 2. The roll load and roll torque is measured for three different experiments. The used material in the figure is Docol $1200 \mathrm{M}$, thickness 1.46 , at the bend angle $60^{\circ}$.

the analytic model for the load as in Eq. (1), Bhattacharyya et al. [8].

\subsection{Power}

The motor current is measured during the forming of Docol $1200 \mathrm{M}$, thickness $1.46 \mathrm{~mm}$. All forming passes are engaged at the same time and the current increases during the forming with $0.6 \pm 0.1 \mathrm{~A}$.
The three-phase power $\left(P_{\text {engine }}\right)$ used to forming the sheet can be calculated as:

$P_{\text {engine }}=\sqrt{3} U \Delta I \cos (\varphi)$

where $U=400 \mathrm{~V}, \Delta I=0.6 \pm 0.1 \mathrm{~A}$ and $\cos (\varphi)=0.83$.

Which gives a power of:

$P_{\text {Engine }}=0.345 \pm 0.057 \mathrm{~kW}$

Table 2

Seven different materials have been formed with the bend angles $20^{\circ}, 40^{\circ}, 60^{\circ}$ and $80^{\circ}$

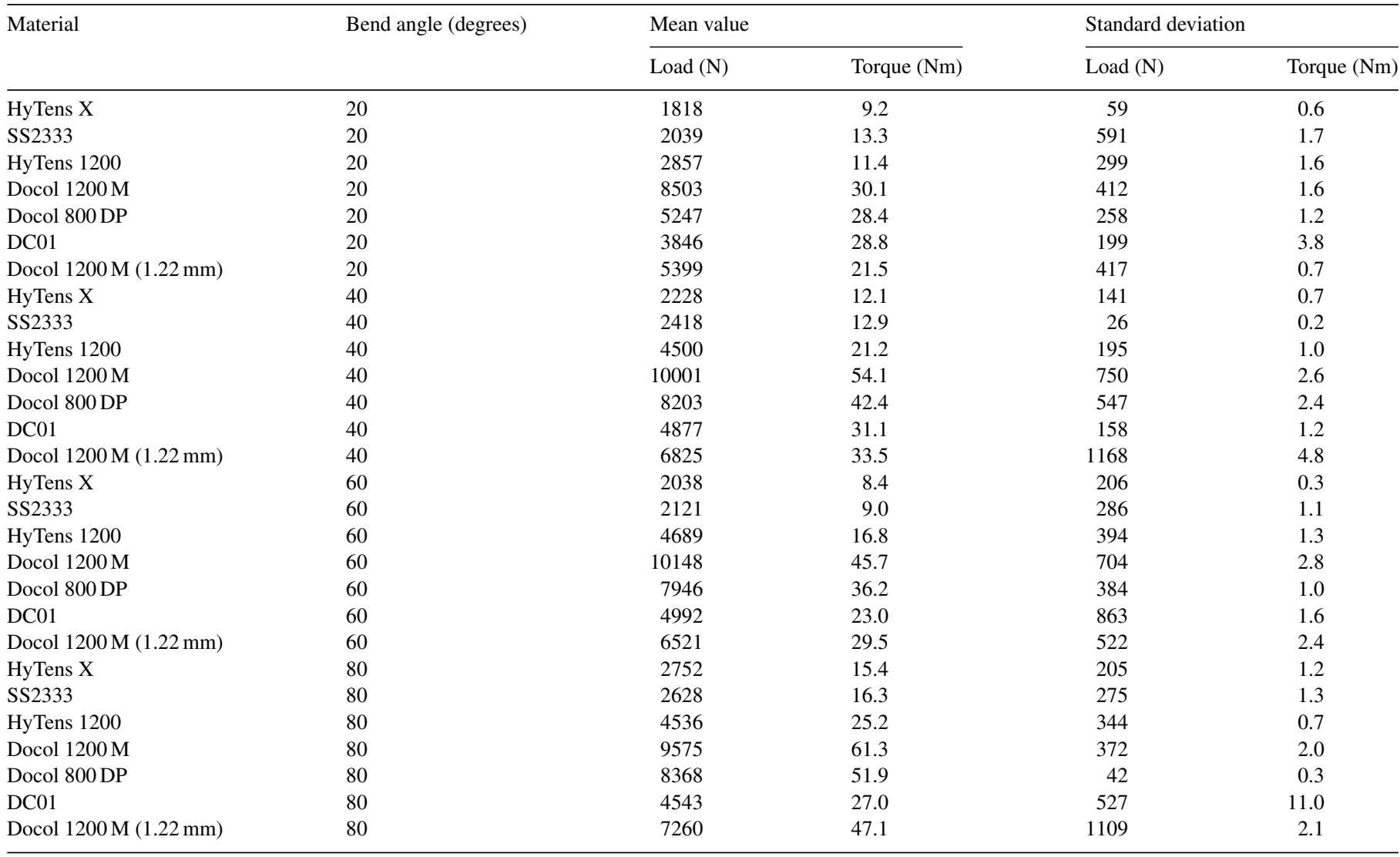

The forming load and the forming torque are measured for all cases. 


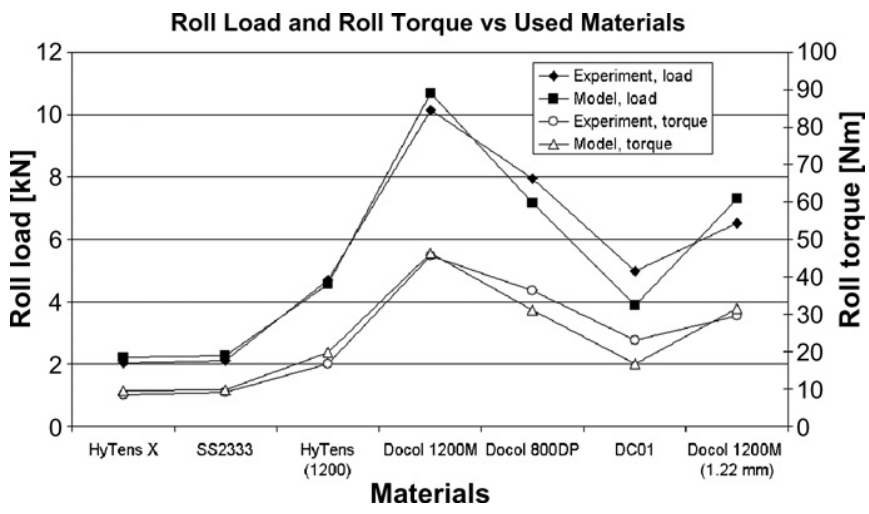

Fig. 3. The models, Eqs. (2) and (3), are compared to the experimental result for the used materials.

The power calculated with help of measured total torque $\left(T_{\text {Total }}\right)$ and measured forming angle velocity is:

$P_{\text {torque }}=T_{\text {Total }} \omega$

where total torque and forming angle velocity for bend angles $20^{\circ}, 40^{\circ}, 60^{\circ}$ and $80^{\circ}$ (Table 2) is:

$$
\begin{aligned}
T_{\text {Total }} & =30.1+54.1+45.7+61.3=191 \mathrm{Nm}, \\
\omega & =2.156 \mathrm{rad} / \mathrm{s}
\end{aligned}
$$

Which gives a power of:

$$
P_{\text {Torque }}=0.411 \mathrm{~kW}
$$

\section{Conclusion}

The results from the experiments can be used to validate and calibrate finite element models. Calculated force will agree fairly well with the measured load provided the material model is correct. The material model can be calibrated by separate material testing. Then the friction coefficient can be adjusted until the torque also agrees well. A lubricant is used in abundance and the surface finish is $R_{Z}=1 \mu \mathrm{m}$ which should give a friction coefficient between 0.05 and 0.1 for Coulomb friction.

Eqs. (2) and (3) give the torque and force required for the bending in a forming step as a function of thickness, material virgin yield strength and bending angle. The calibration of the model gave a good agreement with measurements according to Fig. 3. A consistency check of the measured torque by power comparisons (Eqs. (5) and (8)) in Section 3.2 was done and showed reasonable agreement.

A low production velocity used in the experiments $(v=r \omega$, $r=0.075 \mathrm{~m} \omega=2.156 \mathrm{rad} / \mathrm{s}, v=9.7 \mathrm{~m} / \mathrm{min})$. A more common production speed is $30-40 \mathrm{~m} / \mathrm{min}$. A speed of $40 \mathrm{~m} / \mathrm{min}$ gives a power of $1.7 \mathrm{~kW}$. Thus about $0.5 \mathrm{~kW}$ is required for every forming step when normal production speed is used under conditions similar to those in the current study. It is possible to use of Eq. (3) to estimate the increase in power consumption when changing, for example, the yield strength of the formed material.

\section{Acknowledgements}

The author thanks ORTIC AB, Swedish Knowledge Foundation, Jernkontoret and Dalarna University for their technical and financial support.

\section{References}

[1] S.M. Panton, S.D. Zhu, J.L. Duncan, Fundamental deformation types and sectional properties in roll forming, Int. J. Mech. Sci. 26 (8) (1994) 725735.

[2] M. Kiuchi, T. Koudabashi, Proceeding of the 3rd International Conference on Rotary Metal Working Processes, IFS Ltd and North Holland, September 1984, pp. 423-436.

[3] G.T. Halmos, Roll Forming Handbook (Manufacturing Engineering and Materials Processing), CRC Press, Taylor \& Francis Group, 2006, ISBN 0-8247-9563-6.

[4] C.K. McClure, H. Li, Roll forming simulation using finite element analysis, Manuf. Rev. 8 (1995) 114

[5] M. Brunet, S. Mguil, P. Pol, Modeling of a roll forming process with a combined 2D and 3D FEM code, J. Mater. Process. Technol. 80-81 (1998) 213-219.

[6] M. Lindgren, Finite element model of roll forming of a U-channel profile, in: Presented at International Conference on Technology of Plasticity, Verona, Italy, 2005.

[7] PROFIL, Rollform Design Software, UBECO, www.ubeco.com.

[8] D. Bhattacharyya, P.D. Smith, S.K. Thadakamalla, I.F. Collins, The prediction of roll load in cold roll forming, J. Mech. Work. Technol. 14 (1987) $363-379$.

[9] K.F. Chaing, Cold roll forming, M.E. Thesis, University of Auckland, August, 1984. 